\title{
ILIAC - RENAL BYPASS IN EVAR OF AAA WITH RENAL ARTERIES ARISSING FROM ANEURYSMAL SAC
}

\author{
Petr Utíkal ${ }^{\mathrm{a}}$, Martin Köcher ${ }^{\mathrm{b}}$, Petr Bachleda ${ }^{\mathrm{a}}$, Petr Dráča ${ }^{\mathrm{a}}$, Marie Černác, Eva Buriánkovác
}

\author{
a 2nd Clinic of Surgery, Teaching Hospital Olomouc \\ ${ }^{b}$ Clinic of Radiology, Teaching Hospital Král. Vinohrady Praha \\ c Clinic of Radiology, Teaching Hospital Olomouc, Czech Republic \\ e-mail: petr.utikal@fnol.cz
}

Received: October 10, 2004; Accepted: November 7, 2004

Key words: Aneurysm/Aorta/Treatment/Surgery/Endovascular/Iliacrenal bypass/Combined strategy

The authors describe treatment possibility for AAA with renal arteries arising from aneurysmal sac in high operating risk patients. They combined endovascular stent-grafting for aneurysmal sac exclusion and classical vascular surgical iliacrenal bypass for revascularisation of excluded renal arteries.

\section{INTRODUCTION}

Endovascular AAA repair (EVAR) has gained increasing popularity as an alternative to open AAA surgery over the last decade ${ }^{1-3}$. Unfortunately EVAR has technical limitations caused by present stent-graft systems construction and therefore all AAAs are not suitable for this type of repair. Visceral arteries arising from the aneurysmal sac belong mostly to the exclusion criteria for EVAR due to the high risk of severe organ ischemia connected with aneurysmal sac stent-grafting in such cases ${ }^{4-6}$. Therefore, visceral arteries revascularisation is necessary and associated surgical bypass seems to be the best possibility for that at present.

\section{METHOD}

\section{Patient No 1.}

A 78 year old man of good life quality with AAA, which was diagnosed 3 years ago. The diameter of $50 \mathrm{~mm}$ was the indication for elective treatment. The vascular surgeons thought about open surgery only, and based on the patient's high operating risk, they recommended observation. The AAA diameter growth of $18 \mathrm{~mm}$ in the last year as well as other symptoms led to acute indication for the treatment. We thought about EVAR first, but the AAA morfology was a complicated one. The patient had had his right kidney removed due to tuberculosis many years ago and the main renal artery of the solitary left kidney arose from the aneurysmal sac (Fig. 1).

\section{Patient No 2.}

A 82 year old woman of good life quality but high operating risk with AAA, in which an important lower accessory renal artery arose from the aneurysmal sac on both sides (Fig. 2).
What could we recommend to these for open AAA surgery unfit patients with AAA unsuitable for EVAR? Open AAA surgery could be technically possible, but with a high risk of death due to the patients' condition. On the other hand, EVAR could be adequate, considering their condition, but the renal arteries exclusion could lead to renal function failure with ensuing need of dialysis. Based on all the conclusions, we decided in favor of EVAR associated with surgical revascularisation of renal arteries.

The procedures were conducted with regional (epidural) anesthesia under the basic conditions for vascular surgery (antibiotics, heparinisation). The first step of the procedure was renal and external iliac arteries exposure and bypasses creation. Renal arteries were exposed through extraperitoneal approach on one or both sides. Inflow anastomosis was created with the prosthesis end to the external iliac artery side. Outflow anastomosis was created with the prosthesis end to the side of renal artery perifery part. The blood flow through the bypasses began from the time of its creation. We used ePTFE prosthesis for bypass creation. In the second patient it was possible to make renal artery transposition to the iliac one. Stentgraft implantation was the next step. AAA was excluded using a bifurcated type of stentgraft from the groin access through common femoral arteries. The central part of renal arteries was closed by ligature to prevent retrograde flow.

Primary successful AAA exclusion was achieved in both patients. There were no severe complications in relation to associated surgery. Both patients have been observed for 3 years. All bypasses are primarily open and the function of the revascularised kidneys have been proper. 

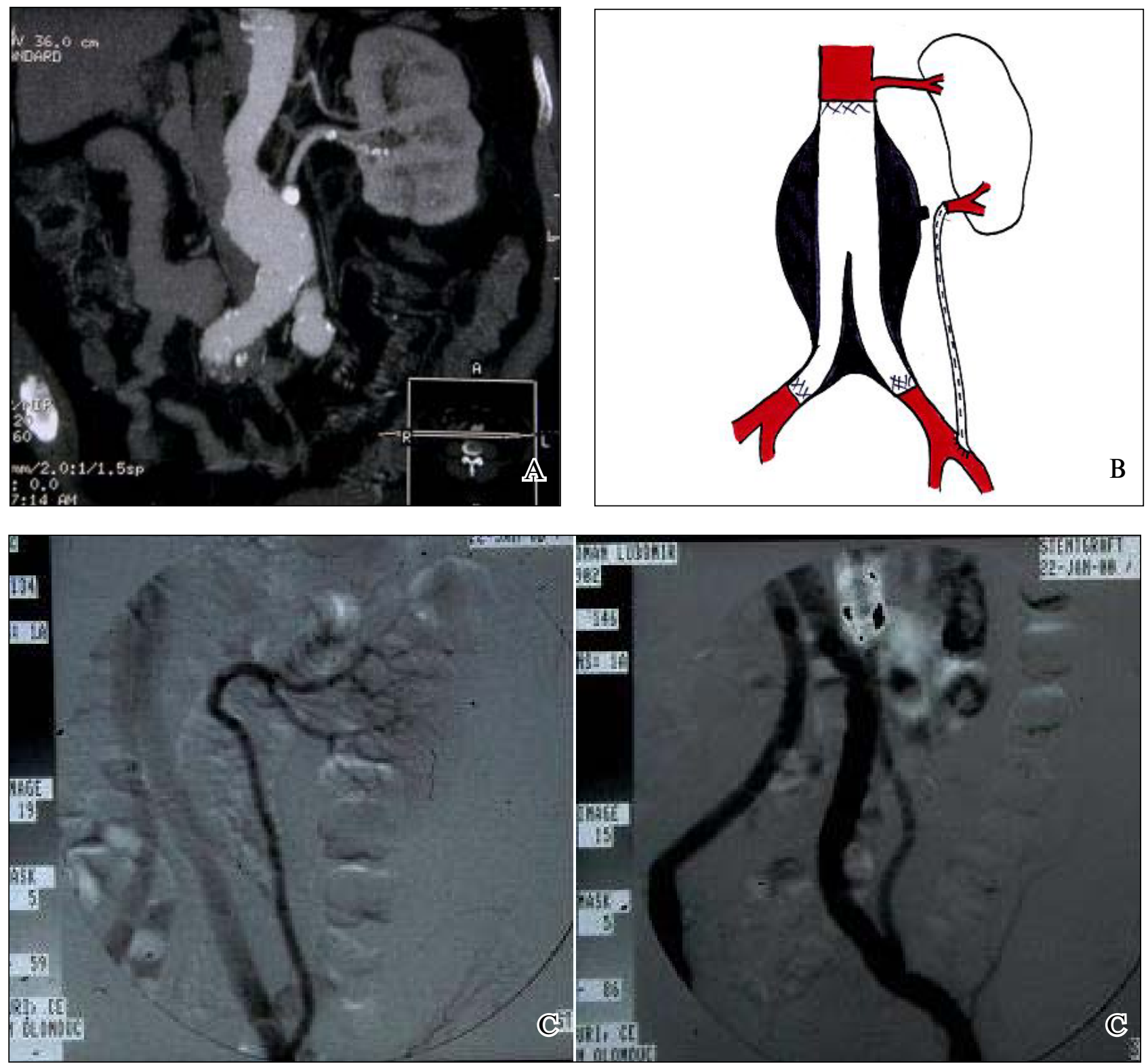

Fig. 1. A 78 year old man with AAA

A: Preoperative CTA of AAA. Solitary kidney on the left side, the main renal artery arising from aneurysmal sac. B: Diagram of AAA repair.

C: Postoperative angiogram of the AAA successful exclusion by a bifurcated type of stent-graft. Renal revascularisation by iliacrenal bypass to the lower renal artery.

\section{DISCUSSION}

Primary association of surgical and interventional radiological procedures is called the combined strategy. On the one hand, it is true that the invasiveness of this combined procedures increases, along with all the consequences ensuing from open surgery. On the other hand, these open surgical procedures in cases of problematic AAA morphology allow for EVAR and the indication for the hemodynamically less stressful non-clamping AAA repair is preserved ${ }^{2}$.

Bypass creation from iliac arteries for revascularisation of the excluded important aneurysmal sac branches is hemodynamically less stressful and the extraperitoneal approach is a miniinvasive one.

We have to mention a branched graft as a treatment possibility in cases of AAA with visceral arteries arising from its sac. From our point of view, this type of stentgraft is not for large clinical use at present ${ }^{7,8}$.

\section{CONCLUSION}

A primary combination of endovascular stentgrafting and classical vascular surgery procedures extends the indications for AAA endovascular treatment. We recommend 

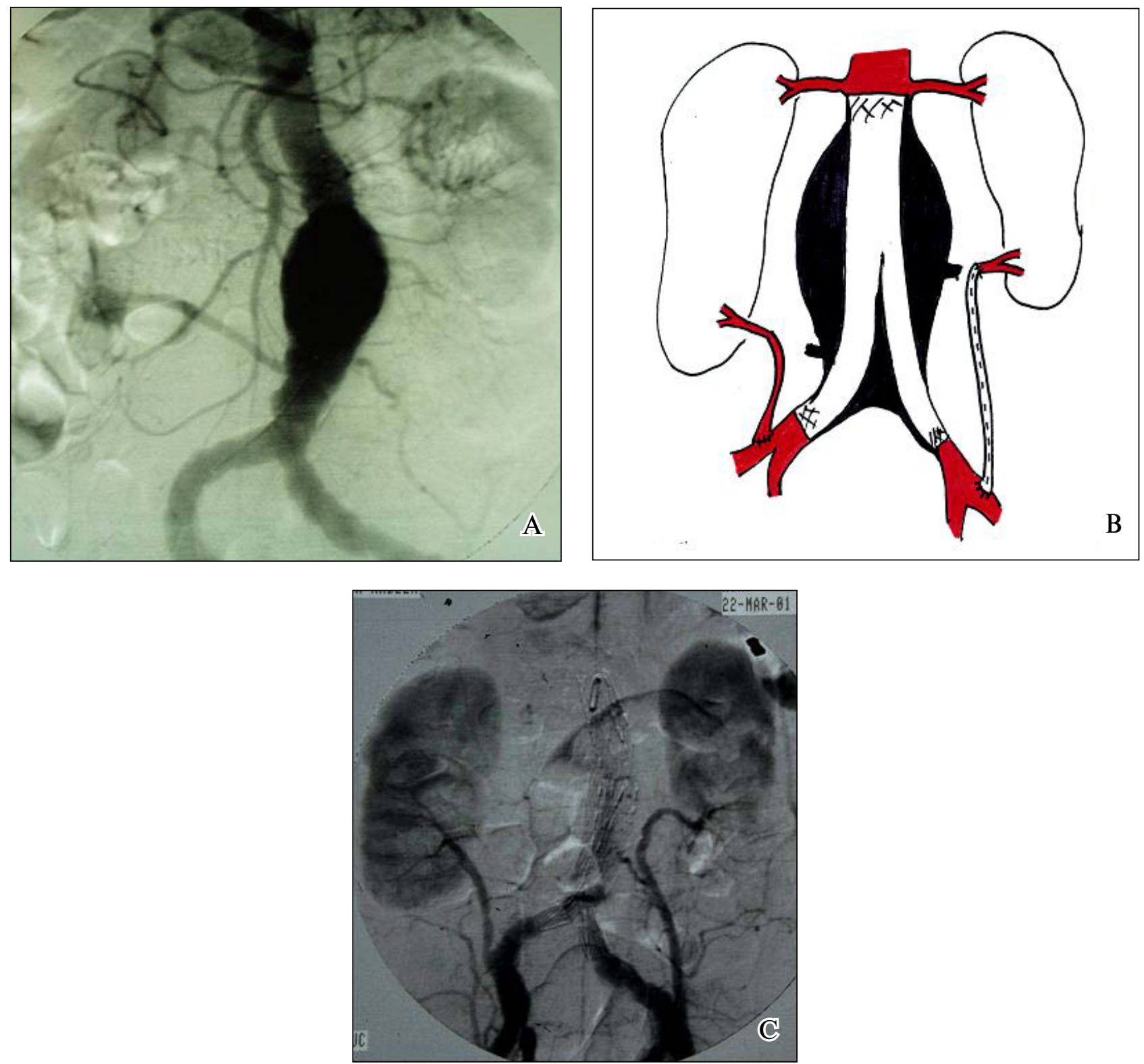

Fig. 2. A 82 year old woman with AAA.

A: Preoperative angiogram of AAA. One of the two equal renal arteries arising from aneurysmal sac on both sides.

B: Diagram of AAA repair.

C: Postoperative angiogram of AAA successful exclusion by bifurcated type of stentgraft. Reimplantation of lower renal artery to common iliac artery on the right side. Iliacrenal bypass to the lower renal artery on the left side.

this "combined strategy" especially for high operating risk patients (unacceptable for open AAA surgery) with complicated AAA morphology (less suitable for EVAR ), who have not any other AAA treatment possibility.

\section{REFERENCES}

1. Parodi JC, Palmaz JC, Barone HD. (1991) Transfemoral intraluminal graft implantation for abdominal aortic aneurysms. Ann Vas Surg 5, 4912-499.
2. Utíkal $\mathrm{P}$, Köcher $\mathrm{M}$, Bachleda $\mathrm{P}$, Dráč $\mathrm{P}$, Buriánková E, Kojecký Z, Ürge J. (2001) Léčba AAA na prélomu tisíciletí - stentgrafting - role cévního chirurga. Prakt Flebol 10(3), 111-113.

3. Köcher M, Utíkal P, , Koutná J, Bachleda P, Buriánková E, Heřman M, Bučil J, Benýšek V, Černá M, Kojecký Z.(2004) Endovascular treatment of abdominal aortic aneurysms-6 years of experience with Ella stent-graft system. Eur J of Radiol 51, 181-188.

4. Schumacher H, Allenberg JR, Eckstein HH. (1996) Morphological classification of abdominal aortic aneurysm in selection of patients for endovascular grafting. Br J Surg 83, 949-950.

5. Carpenter JP, Baum RA, Barker CF. (2001) Impact of exclusion criteria on patient selection for endovascular abdominal aortic aneurysm repair. J Vasc Surg 34, 1050-1054. 
6. Schumacher H, Eckstein HH, Kallinowski F. Morphometry and classification in abdominal aortic aneurysms: patient selection for endovascular and open surgery. J Endovasc Surg 4, 39-44.

7. Vos AWF, Linsen MAM, Wisselink W, Rauwerda JA. (2004) Endovascular grafting of complex aortic aneurysms with a modular side branch stent-graft system in a porcine model. Eur J Vasc Endovasc Surg 27, 492-497.

8. Greenberg RK, Haulon S, O’Neil S, Lyden S, Ouriel K. (2004) Primary endovascular repair of juxtarenal aneurysms with fenestrated endovascular grafting. Eur J Vasc Endovasc Surg 27, 484-491. 